\title{
PENGARUH MODEL PEMBELAJARAN KOOPERATIF TIPE GROUP INVESTIGATION(GI) TERHADAP HASIL BELAJAR FISIKA PADA MATERI POKOK LISTRIK DINAMIS DI SMA AMIR HAMZAH MEDAN
}

\author{
Erni Afdalita dan Purwanto \\ erniafdalita@yahoo.co.id \\ Jurusan Fisika FMIPA Universitas Negeri Medan \\ Jalan Willem Iskandar Pasar V Medan, 20221
}

\begin{abstract}
The purpose of this study was to determine the effect of cooperative learning model group investigation on learning outcomes in the subject matter physics dynamic electricity in SMA Amir Hamzah Medan. This type of research is quasi-experimental. The population of this entire class X SMA Amir Hamzah Medan. The sample in this study was taken as a random sampling of two classes. The instrument used to determine student learning outcomes in the material dynamic electricity in the form of multiple-choice questions numbered 20. The t test hypothesis testing premises of the parties. Through the t test of the obtained results of student learning using learning model group investigation higher than conventional learning, so it is concluded that there is a significant relationship between the use of cooperative learning model group investigation on student learning outcomes.
\end{abstract}

Keywords : Cooperative learning model group investigation, learning outcomes.

\section{PENDAHULUAN}

Salah satu masalah yang dihadapi dunia pendidikan adalah proses pembelajaran. Dalam proses pembelajaran, anak kurang didorong untuk mengembangkan kemampuan berpikir. Proses pembelajaran di dalam kelas diarahkan kepada kemampuan anak untuk menghafal informasi dan otak anak dipaksa untuk mengingat dan menimbun berbagai informasi tanpa dituntut untuk memahami informasi yang diingatnya itu untuk menghubungkannya dengan kehidupan sehari-hari. Akibatnya, siswa dalam proses pembelajaran kurang berpartisipasi, hal ini menyebabkan kurangnya minat siswa dalam pelajaran fisika dan mengakibatkan hasil belajar mata pelajaran fisika yang diperoleh siswa rendah.

Sesuai dengan wawancara yang dilakukan oleh penulis kepada salah seorang guru fisika di SMA Amir Hamzah Medan beliau mengatakan mengatakan bahwa kegiatan belajar mengajar masih cenderung menggunakan pembelajaran konvensional dengan metode ceramah dan diskusi. Selain itu, nilai Fisika siswa belum mencapai standar Kriteria Ketuntasan Minimum (KKM) yaitu 70. Berdasarkan studi pendahuluan 
yang dilakukan penulis melalui instrument angket yang diberikan kepada 30 orang responden di kelas X SMA Amir Hamzah Medan yang berisi tentang pertanyaanpertanyaan tentang aktivitas, minat dan motivasi siswa terhadap pelajaran fisika. Hasilnya diperoleh $12,5 \%$ saja siswa yang menyukai mata pelajaran Fisika, 56,25\% siswa menyatakan bahwa mata pelajaran fisika itu sulit tapi menarik, 15,62\% menyatakan sulit dan tidak menarik, $15,62 \%$ menyatakan biasa saja, karena materi fisika banyak menggunakan rumus dan perhitungan sehingga siswa bosan, Dari data tersebut terlihat bahwa sebagian besar siswa kurang menyukai pelajaran fisika karena mereka menganggap pelajaran fisika selalu identik dengan rumusan matematika yang sulit untuk dihafal. Akibatnya, siswa cenderung pasif dalam keterlibatan proses belajar mengajar dan jarang bertanya kepada guru apabila ada materi pelajaran yang kurang dimengerti. Berdasarkan masalah tersebut, perlu melakukan pembenahan dalam mengatasi pembelajaran teacher centered penulis ingin mencoba melakukan model pembelajaran kooperatif tipe Group Investigation saebagai salah satu alternative untuk memecahkan masalah-masalah diatas dalam upaya meningkatkan hasil belajar siswa. Group Investigation merupakan salah satu bentuk pembelajaran kooperatif yang menekankan pada partisipasi dan aktivitas siswa untuk mencari sendiri materi atau informasi pelajaran yang akan dipelajari melalui bahan-bahan yang tersedia, misalnya dari buku pelajaran atau siswa dapat mencari melalui internet. Siswa dilibatkan sejak perencanaan, baik dalam menentukan topik maupun cara untuk mempelajarinya melalui investigasi.

Menurut Slavin (2005), dalam belajar kooperatif siswa dibentuk dalam kelompok-kelompok yang terdiri dari 4 atau 5 orang untuk bekerja sama dalam menguasai materi yang diberikan guru. Tipe GI merupakan salah satu model pembelajaran yang dapat melibatkan siswa secara aktif sejak perencanaan pemebelajaran, baik dalam menentukan topik yang akan dibahas maupun cara untuk mempelajarinya melalui investigasi kelompok sehingga dapat digunakan untuk mengatasi masalah pembelajaran fisika. Harapannya agar terjadinya pembelajaran bermakna sesuai dengan paradigma konstruktivistik. Artinya, dalam pembelajaran ini kegiatan aktif dengan pengetahuan dibangun sendiri oleh siswa dan mereka bertanggung jawab atas hasil pembelajarannya. Konsep model pembelajaran Group Investiagtion ini mengajarkan suatu konsep atau materi pokok dengan menerapkan tiga konsep utama, yaitu: penelitian (inquiry), pengetahuan (knowledge), dan (3) dinamika belajar kelompok (the dynamics of the learning group).

\section{METODE PENELITIAN}

Penelitian ini dilaksanakan di SMA Amir Hamzah Medan yang beralamat di Jalan Meranti No.1, Medan dan pelaksanaannya pada bulan Maret-April 2014 di semester II Tahun Pembelajaran 2013/2014.

Penelitian ini termasuk jenis penelitian quasi eksperimen yang melibatkan dua kelas yang diberi 
model pembelajaran yang berbeda. Kelas eksperimen menggunakan model pembelajaran kooperatif tipe Group Invstigation sedangkan di kelas kontrol menggunakan pembelajaran konvensional. Desain penelitian ini dapat dilihat pada Tabel 1.

Tabel 1. Pretest-Postest Design

\begin{tabular}{|l|c|c|c|}
\hline Kelas & Pretes & Perlakuan & Postes \\
\hline Eksperimen & $\mathrm{T}_{1}$ & $\mathrm{X}$ & $\mathrm{T}_{2}$ \\
Kontrol & $\mathrm{T}_{1}$ & - & $\mathrm{T}_{2}$ \\
\hline
\end{tabular}

Keterangan :

$$
\begin{aligned}
\mathrm{X}_{1}= & \begin{array}{l}
\text { Pembelajaran dengan } \\
\text { kooperatif } \\
\text { Investigation }
\end{array} \\
&
\end{aligned}
$$

$\mathrm{T}_{1}=$ Pemberian pretes

$\mathrm{T}_{2}=$ Pemberian postes

Uji Lilliefors digunakan untuk mengetahui apakah sampel beristribusi normal atau tidak. Uji homogenitas digunakan untuk mengetahui apakah data mempunyai varians yang homogen atau tidak. Uji homogenitas menggunakan uji kesamaan varians Pengujian hipotesis digunakan uji $t$. ( Sudjana, 2005).

Sintaks model pembelajaran kooperatif tipe Group Investigation diadopsi dari (Trianto, 2010) seperti ditunjukkan pada table 2 :
Tabel 2. Sintaks model pembelajaran kooperatif tipe Group Investigation.

\begin{tabular}{|l|l|}
\hline \multicolumn{1}{|c|}{ Fase } & \multicolumn{1}{c|}{ Aktivitas guru } \\
\hline $\begin{array}{l}\text { Fase-1 } \\
\text { Pemilihan } \\
\text { Topik. }\end{array}$ & $\begin{array}{l}\text { Guru menetapkan } \\
\text { masalah yang akan di } \\
\text { diskusikan oleh para siswa. } \\
\text { Membagi siswa ke dalam } \\
\text { kelompok secara heterogen }\end{array}$ \\
\hline $\begin{array}{l}\text { Fase-2 } \\
\text { Perencana } \\
\text { an }\end{array}$ & $\begin{array}{l}\text { Guru menjelaskan prosedur } \\
\text { pembelajaran dan tugas untuk } \\
\text { kara siswa. } \\
\text { Guru membagikan LKS serta } \\
\text { menugaskan siswa untuk } \\
\text { melakukan investigasi } \\
\text { (penyelidikan). }\end{array}$ \\
\hline $\begin{array}{l}\text { Fase-3 } \\
\text { Implement } \\
\text { asi. }\end{array}$ & $\begin{array}{l}\text { Guru mengikuti kemajuan } \\
\text { tiap kelompok dan } \\
\text { menawarkan bantuan bila } \\
\text { diperlukan. }\end{array}$ \\
\hline $\begin{array}{l}\text { Fase-4 } \\
\text { Analisis } \\
\text { dan } \\
\text { sintesis. }\end{array}$ & $\begin{array}{l}\text { Guru memantau siswa dalam } \\
\text { membuat bahan presentasi }\end{array}$ \\
\hline $\begin{array}{l}\text { Fase-5 } \\
\text { Presentasi } \\
\text { hasil }\end{array}$ & $\begin{array}{l}\text { Guru mengkoordinasi siswa } \\
\text { dalam melakukan presentasi }\end{array}$ \\
\hline $\begin{array}{l}\text { Fase-6 } \\
\text { Evalusi }\end{array}$ & $\begin{array}{l}\text { Guru bersama dengan siswa } \\
\text { merangkum materi pelajaran }\end{array}$ \\
\hline
\end{tabular}

\section{HASIL DAN PEMBAHASAN}

\section{A. Hasil Penelitian}

Berdasarkan hasil penelitian diperoleh data yang dideskripsikan untuk pretes pada kelas eksperimen dan kelas kontrol. Sebelum pembelajaran (pretes) yang bertujuan untuk mengetahui apakah kemampuan awal siswa pada kedua kelompok kelas sama atau tidak. Berdasarkan data hasil penelitian yaitu pada kelas eksperimen memiliki rata-rata pretes sebesar 36,83 sedangkan untuk kelas kontrol memperoleh nilai rata-rata 34,5 . Untuk lebih jelasnya distribusi data pretes siswa kedua kelas tersebut dapat divisualisasikan dalam diagram batang pada Gambar 1 . 


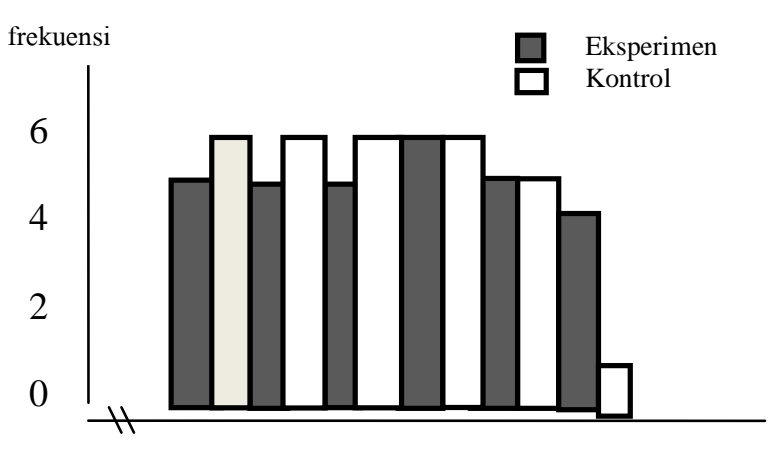

$\begin{array}{lllllll}19,5 & 25,5 & 31,5 & 37,5 & 43,5 & 49,5 & \text { Nilai }\end{array}$

Gambar.1. Diagram Batang Data Pretes Siswa

Berdasarkan gambar 1 menunjukkan bahwa nilai pretes pada kelas eksperimen dan kelas kontrol tidak jauh berbeda, artinya kedua kelas mempunyai kemampuan awal yang hampir sama dan perolehan nilai kedua kelas merata. Kemudian kedua kelas sampel diberikan perlakuan yang berbeda, pada kelas eksperimen diberikan perlakuan dengan menerapkan model pembelajaran kooperatif tipe group investigation sedangkan pada kelas kontrol diberikan perlakuan dengan menerapkan pembelajaran konvensional. Setelah kedua kelas diberikan perlakuan yang berbeda, kedua kelas selanjutnya diberikan postes dengan soal yang sama seperti soal pretes. Hasil yang diperoleh adalah, nilai rata-rata postes kelas eksperimen setelah menggunakan pembelajaran model kooperatif tipe group investigation adalah: 67,33 , sedangkan pada kelas kontrol dengan menggunakan pembelajaran konvensional memperoleh nilai rata-rata 60,66 . Nilai postes siswa kedua kelas tersebut dapat divisualisasikan dalam diagram batang 2 .

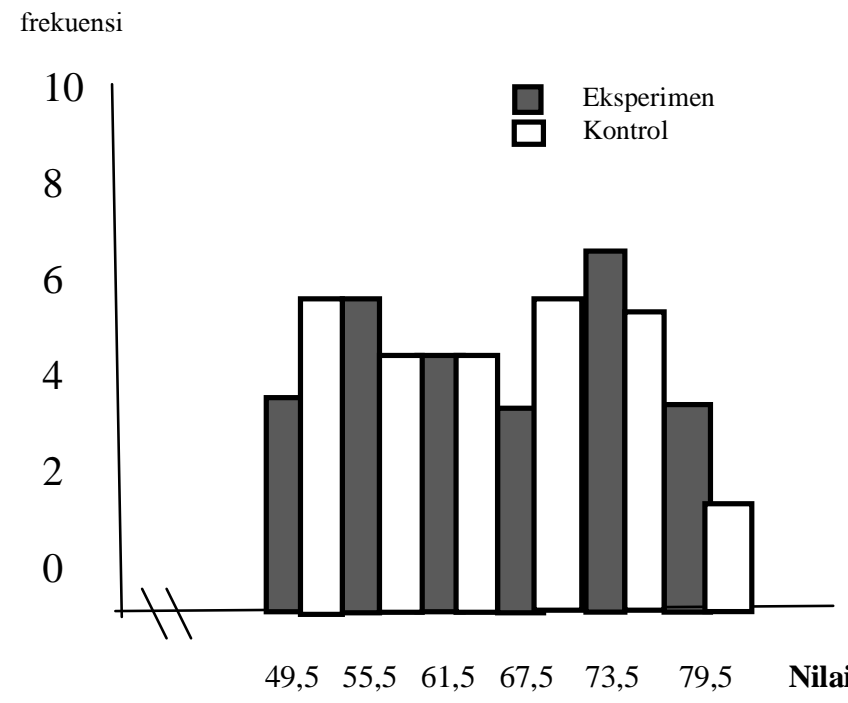

Gambar .2. Diagram Batang Data Postes Siswa

Berdasarkan gambar 2 menunjukkan bahwa hasil belajar di kelas eksperimen lebih baik dari pada di kelas kontrol. Hal ini dapat dilihat dari hasil perolehan postes siswa di kelas eksperimen umumnya lebih tinggi dari kelas kontrol.

Berdasarkan data di atas menunjukkan bahwa model pembelajaran kooperatif tipe Group Investigation dapat meningkatkan hasil belajar siswa di kelas eksperimen. Di samping itu dalam penelitian ini juga dilakukan penilaian sikap dan keterampilan. Pada penilaian sikap siswa mengalami peningkatan dari pertemuan awal hingga akhir di kelas eksperimen dengan rata-rata $60,88 \%$ (aktif), dan di kelas kontrol $53,42 \%$

(cukup aktif). Demikian pada penilaian keterampilan siswa mengalami peningkatan dari pertemuan awal penelitian hingga akhir di kelas eksperimen dengan rata-rata $61,82 \%$ (aktif) dan di kelas kontrol 44,87\% (cukup aktif). Dari data di atas terlihat bahwa peningkatan hasil belajar siswa 
diimbangi dengan peningkatan sikap, dan keterampilan siswa. Keaktifan siswa pada proses pembelajaran sangat mempengaruhi hasil belajar siswa. Pada umumnya siswa yang aktif dalam proses pembelajaran akan memiliki hasil belajar yang tinggi. Tetapi dalam penelitian ini, tidak semua siswa yang aktif dalam pembelajaran memiliki hasil belajar yang tinggi dan sebaliknya. Hal ini menurut peneliti adalah hal yang wajar karena setiap individu memiliki kemampuan yang berbeda. Tetapi pada umumnya siswa yang aktif dalam pembelajaran akan memiliki hasil belajar yang tinggi.

\section{B. Pembahasan}

Model pembelajaran kooperatif tipe Group Investigation (GI) siswa lebih tertarik dan menekankan pada partisipasi dan aktivitas siswa untuk mencari sendiri materi atau informasi pelajaran yang akan dipelajari melalui bahan-bahan yang tersedia,. Keunggulan dari group investigation siswa melakukan pengamatan, merangkai, menanya, menalar dan mengkomunikasikan dalam kegiatan pembelajaran sehingga keterlibatan siswa dalam pembelajaran lebih tinggi. Hasil dari model pembelajaran kooperatif tipe Group Investigation tujuannya bisa mencapai kognitif tinggi berbeda halnya dengan model konvensional yang hanya sampai tujuan kognitif rendah.

Perbedaan hasil belajar tersebut disebabkan oleh kelebihan model pembelajaran kooperatif tipe GI yang tidak mengharuskan siswa menghapal fakta tetapi sebuah model yang membimbing para siswa untuk menemukan sendiri pengetahuan melalui masalah yang di berikan. Hal ini juga didukung oleh teori konstruktivisme bahwa dalam model pembelajaran ini pengetahuan dibangun oleh siswa sendiri secara aktif baik melalui proses personal maupun sosial. Guru harus selalu merancang kegiatan yang merujuk pada kegiatan menemukan salah satunya dengan cara siswa melakukan percobaan (Trianto, 2009).

Keadaan di atas sejalan dengan beberapa hasil penelitian yang menggunakan model pembelajaran kooperatiif tipe $G I$, diantaranya Simbolon (2012) di SMA Negeri 1 Kecamatan Binjai pada materi pokok Listrik Dinamis diperoleh nilai rata-rata pretes kelas eksperimen sebesar 30.88 dan nilai rata-rata postes sebesar 71.50. Pada kelas kontrol diperoleh nilai ratarata pretes siswa sebesar 29 dan nilai rata-rata postes sebesar 62 . Aktivitas siswa selama mengikuti pembelajaran dengan menggunakan model pembelajaran kooperatif tipe GI pada materi pokok Listrik Dinamis diperoleh skor rata-rata aktivitas siswa mencapai $78 \%$ dengan kategori aktif.

Peneliti

selanjutnya Simanjuntak (2013) di SMA Negeri 11 Medan pada materi pokok Listrik Dinamis diperoleh diperoleh nilai rata-rata pretes kelas eksperimen sebesar 32.8 dan nilai rata-rata postes sebesar 76. Pada kelas kontrol diperoleh nilai rata-rata pretes siswa sebesar 32.5 dan nilai rata-rata postes sebesar 66 . Aktivitas siswa selama mengikuti pembelajaran dengan menggunakan model pembelajaran kooperatif tipe GI pada materi pokok Listrik Dinamis diperoleh skor rata-rata 
aktivitas siswa mencapai 63\% dengan kategori aktif.

\section{KESIMPULAN DAN SARAN Kesimpulan}

Berdasarkan hasil penelitian yang diperoleh dari hasil analisa data dan pengujian hipotesis maka dapat disimpulkan:

Hasil belajar fisika siswa yang diberi pembelajaran dengan model pembelajaran kooperatif tipe $G I$ secara individu sebanyak 15 orang sebesar $50 \%$ tuntas, dan dalam kelas belum tuntas, sedangkan menggunakan pembelajaran konvensional secara individu sebanyak 8 orang sebesar $26,6 \%$ tuntas, dan dalam kelas belum tuntas.

Berdasarkan hasil perhitungan uji t diperoleh bahwa ada pengaruh menggunakan model pembalajaran kooperatif tipe GI (Group Investigation) terhadap hasil belajar fisika pada materi pokok Listrik Dinamis di kelas X SMA Amir Hamzah Medan.

\section{Saran}

Berdasarkan hasil penelitian ini, peneliti mempunyai beberapa saran,yaitu : Bagi siswa, khususnya siswa SMA Amir Hamzah Medan hendaknya selalu melakukan persiapan belajar agar diperoleh hasil belajar yang lebih baik dan dalam kelompok hendaknya semua lebih berperan agar tidak ada siswa yang lebih dominan dalam kerja kelompok.

\section{DAFTAR PUSTAKA}

Simbolon, A., (2012), Pengaruh Model Pembelajaran

Koooperatif Tipe Group Investigation (GI) terhadap Hasil Belajar Siswa pada
Materi Pokok Listrik Dinamis di Kelas X Semester II SMA Negeri 1 Kecamatan Binjai T.A. 2011/2012, Skripsi, FMIPA , Universitas Negeri Medan.

Simanjuntak, S., (2013), Pengaruh Model Pembelajaran

Koooperatif Tipe Group Investigation (GI) terhadap Hasil Belajar Siswa pada Materi Pokok Listrik Dinamis di Kelas X Semester II Sma Negeri $11 \quad$ Medan T.A.2012/2013, Skripsi, FMIPA, Universitas Negeri Medan.

Slavin, R. E., (2005), Cooperatif Learning, Penerbit Nusa Media, Bandung.

Sudjana, N., (2005), Metode Statistika, Penerbit Tarsio, Bandung.

Trianto, (2009), Mendesain Model Pembelajaran InovatifProgresif, Penerbit Kencana, Jakarta. 